\section{AFM as a Problem-Solving Tool in the Graphic Arts}

Dr. Robert Bassemir, Gail Costello, and Juanita Parris SunChemical Corporation, Carlstadt, New Jersey

Optical and electron microscopy have been used extensively as problem solving tools in the graphic arts industry. Atomic force microscopy (AFM) is a complementary tool to optical and electron microscopy - it provides a high resolution view of areas $150 \mathrm{~mm}$ by $150 \mathrm{~mm}$ and smaller. Images may be viewed in three dimensions and imaging can take place in either air, under liquid, or in a vacuum.

AFM can be used for more than just the three-dimensional imaging of nanoscale features on a sample surface; it can detect friction, adhesion, compliance, thermal properties, and even magnetic signals. AFM images are stored digitally and so the data can be enhanced and viewed in many ways. Algorithms allow the display of a line profile across the image surface at any desired location along with quantitative height information. Average roughness data can also be calculated.

The use of AFM has primarily been in the semiconductor, life sciences, and material science fields - and AFMs are currently emerging in the process environment. The graphic arts field, however, is an area that is not often thought of as an application of AFM. The following are examples of how the AFM was used as the preferred method in solving ink adhesion-related problems in the graphic arts field.

\section{Packaging Print Slip}

The large variation in the coefficient of friction between two candy packages printed with different inks and different cold seal release lacquers was investigated using the AFM. No significant difference was seen using SEM, but the AFM revealed that the wax particles present on both prints varied both in particle size and frequency of distribution on the surface (see figures 1). The sample having good slip is shown in the upper left illustration and both the large and small particles of the slip agents can be easily seen along with a reasonably high population of these particles. The upper right figure with the poor slip shows a deficiency of particles in many areas and only a few of the larger particles which are needed to prevent contact abrasion.

\section{Scratches on Preprint Packaging Board Prints}

A customer complaint of marking of partly overcoated flexo prints on preprint board with scratches was being blamed on the printing operation. Optical microscopy could not reveal when the damage occurred, due to its lack of depth, of focus, and resolution. A topographic scan using AFM clearly showed that the scratches had occurred after printing and coating had taken place. It most likely occurred during the handling steps after leaving the press and coater. The reason for this conclusion had to do with the sharp edges of the grooves and displaced coating and ink particles which are clearly evident in the three-dimensional AFM image. If coating or printing had occurred after the scratches were made, these sharp edges and particles would have been covered with either ink or coating and not be clearly evident. (See figures 2 and 3). At the bottom of each image, a toolbox analysis using the software of the AFM allows one to draw a cross-sectional profile of the surface at any position desired. This also yields quantitative data on the depth and shape of the scratches in the specimens, which can help to identify the source of the damage.

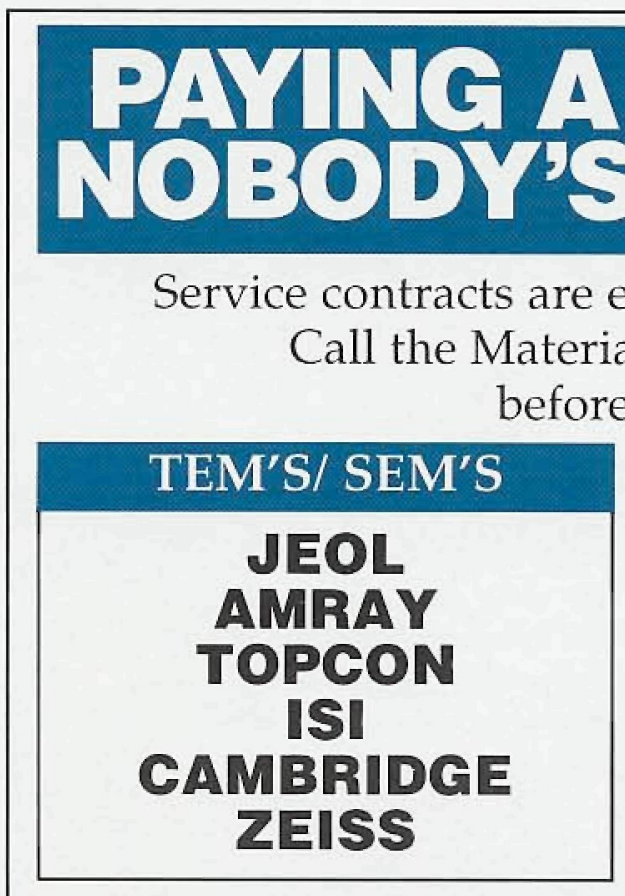

WE SERVICE

COMPUTER CONTROLLERS $X$-RAY SPECTROMETERS BEAM BLANKERS WATER CHILLERS

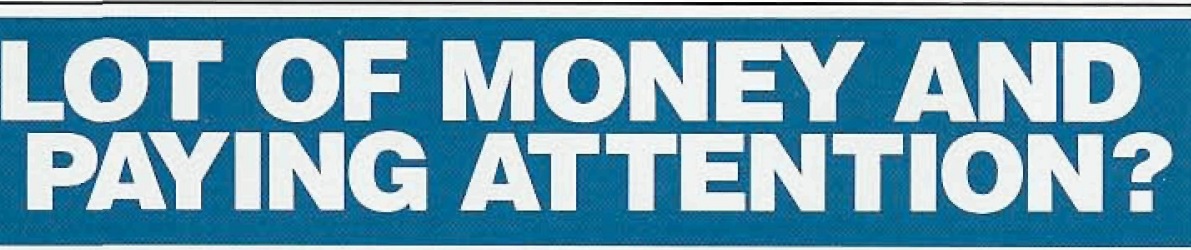

xpensive. Are you getting the service you paid for?

Analytical Services' EM SERVICE GROUP you sign another Service Contract.

\begin{tabular}{|cc|}
\hline ULTRAMICROTOMES \\
\hline DUPONT & RMC \\
MT-1 & MT-5000 \\
MT-2 & MT-6000 \\
MT-2B & MT-7000 \\
MT-2C & CRYO
\end{tabular}

PREP EQUIPMENT

VACUUM COATERS SPUTTER COATERS MECHANICAL PUMPS TURBO PUMPS PLASMA ASHERS

Contracts and On-Demand

Emergency Service at

Reasonable Rates from

Factory Trained Specialists. 1-800-421-8451
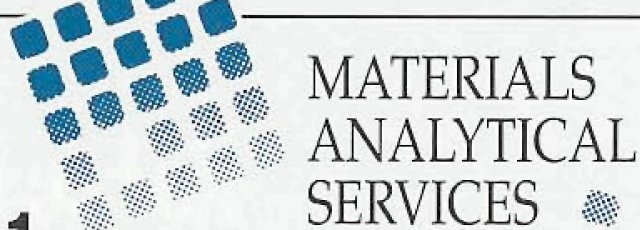

ADVANCED ANALYTICAL PRODUCTS AND SERVICES

3597 Parkway Lane • Suite 250 - Norcross, Georgia 30092 - 770-448-3200 • FAX 770-368-8256 or 616 Hutton Street • Suite 101 - Raleigh, North Carolina 27606 • 919-829-7041 • FAX 919-829-5518 


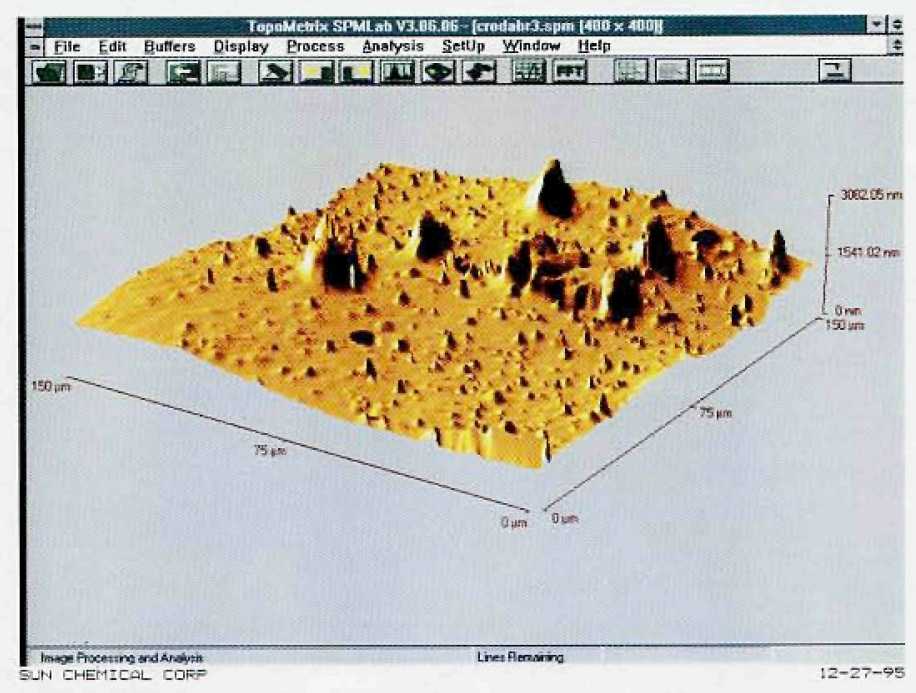

Figure 1A: Good slip - poly film candy bar wappers

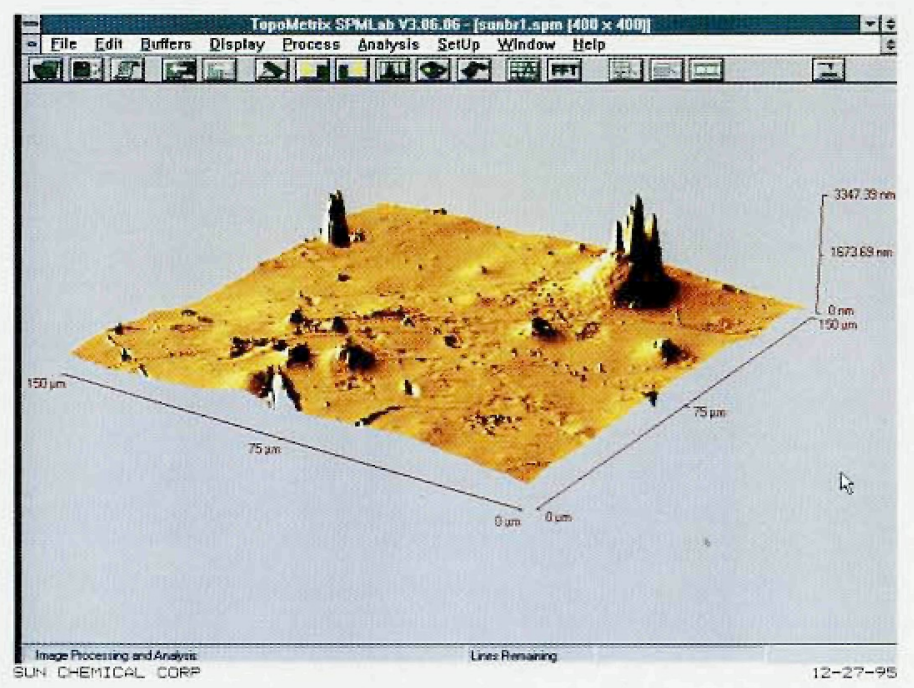

Figure 1B: Poor slip - poly film candy bar wrappers

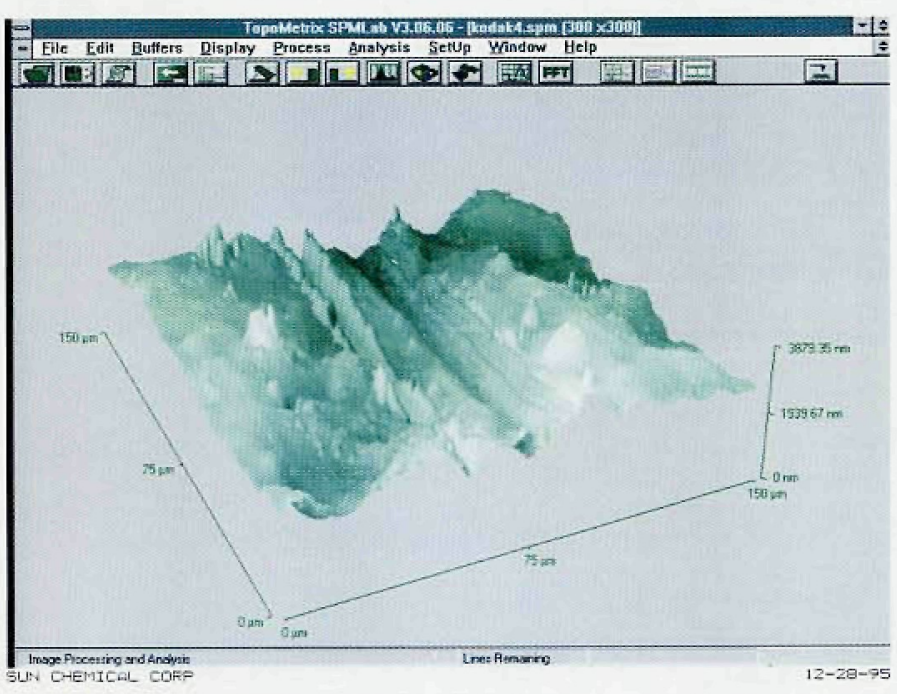

Figure 2A: Grey ink with overprint varnish

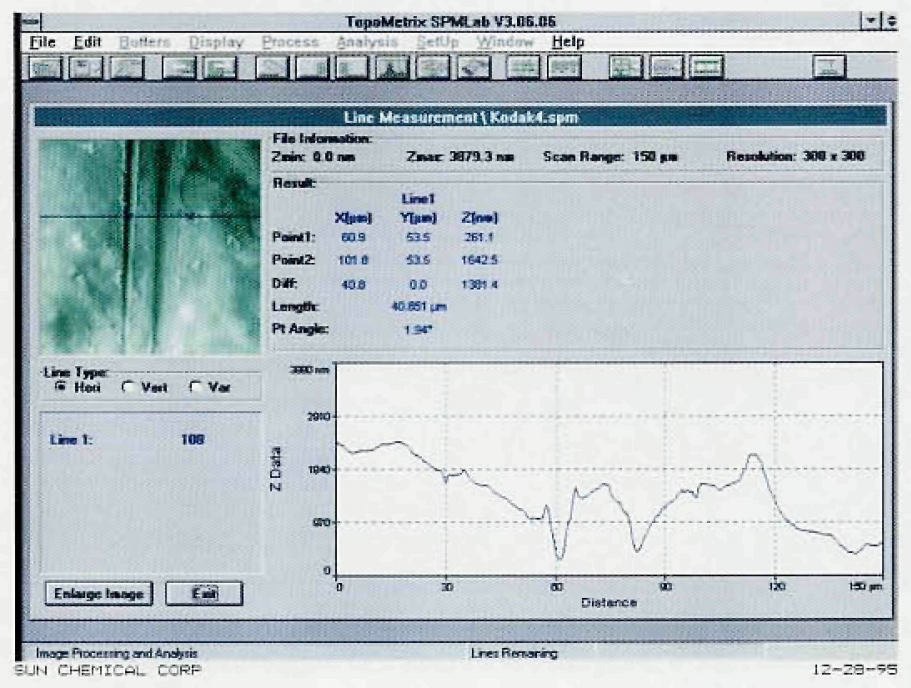

Figure 2B: Toolbox analysis: Grey ink with overprint varnish

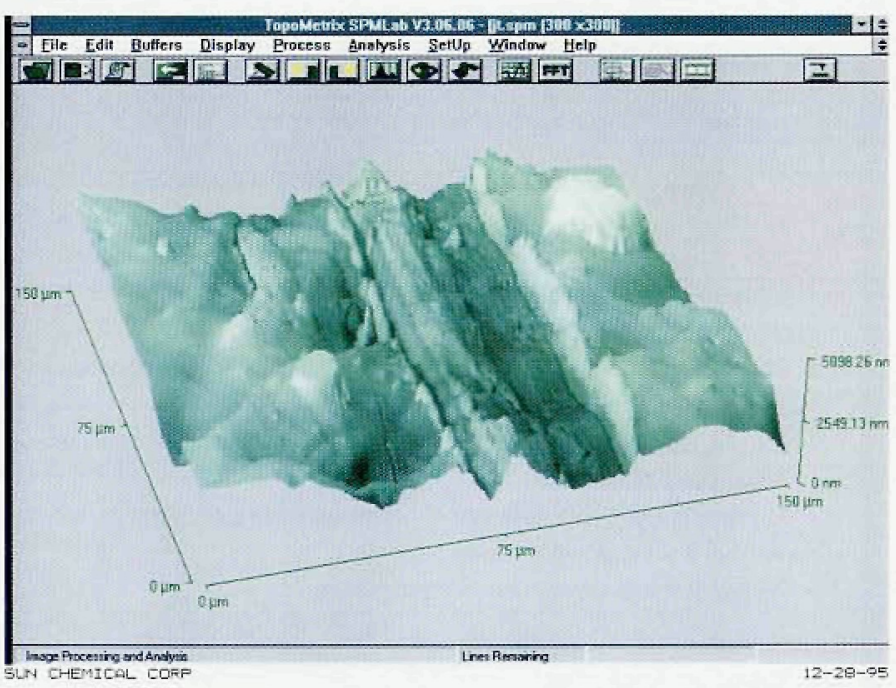

Figure 3A: Black ink, no overprint varnish

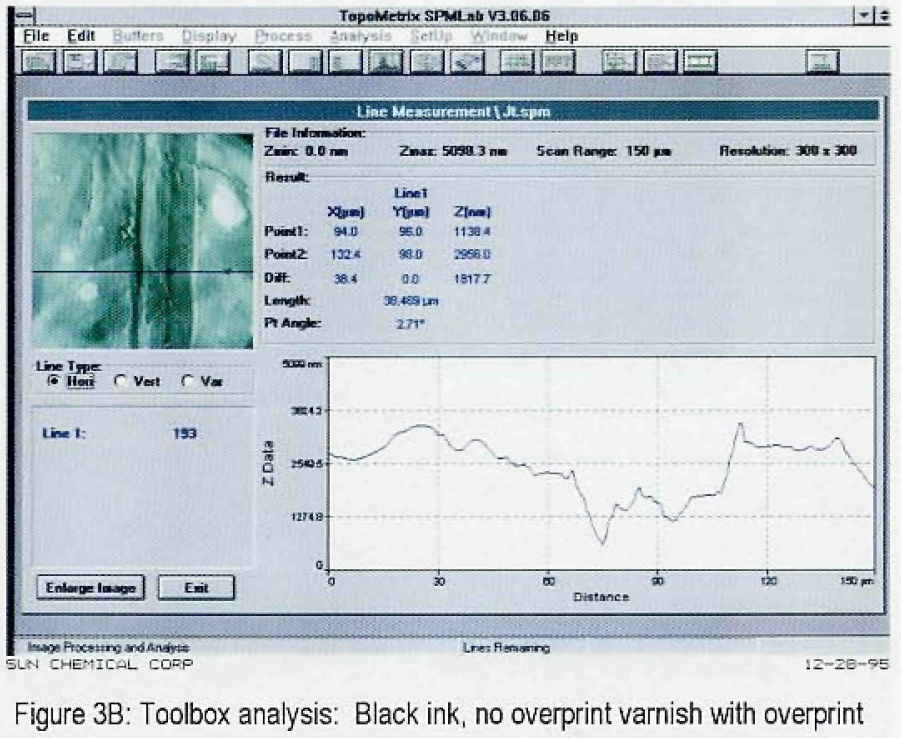

